\title{
Editorial
}

\section{Physics Is Its History}

Here is a radical view: in the final analysis, physics cannot be separated from "the history of physics." Physics is its history. This claim appears radical because physicists of each generation inherit a set of problems that they are told urgently need addressing, a set of concepts and instruments with which to address them, and an idea of how to move forward. Physicists are occupied with that task of moving forward and might see no pressing need to understand exactly how they got the set of problems, concepts, and instrument that points the way forward.

But knowing how the process of inheritance constrains that path is often key to overcoming otherwise insurmountable obstacles. Furthermore, history of physics cannot be understood without the kind of insight into its nature and significance that one gets from philosophy-both from searching reflection and questioning and from the philosophical texts that best exemplify that kind of hard thinking. This breaks with the usual view that physics, as a scientific endeavor, stands apart from history and philosophy, considered as part of the humanities, or perhaps the social sciences, but not the natural sciences as such.

We nevertheless find ample reason to think of physics as integrated with history and philosophy. First of all, until recently, the most influential physicists were steeped in the developments that had preceded their own work and the texts in which their predecessors presented their understanding and its rationale. Newton studied Aristotle, Descartes, and Galileo carefully, as his own writings reveal. James Clerk Maxwell wrote that "it is of great advantage to the student of any subject to read the original memoirs on that subject, for science is always most completely assimilated when it is in its nascent state." 1

Albert Einstein constantly referred to the work of the great physicists (though sometimes he was casual in his footnotes) as well as to philosophers; as a teenager, he devoured Kant's writings and later called himself a "disciple of Spinoza." In a 1944 letter to the African-American physicist Robert Thornton, Einstein argued that "a knowledge of the historic and philosophic background gives that kind of independence from prejudices of his generation from which most scientists are suffering. This independence created by philosophical thought is - in my opinion-the mark of distinction between a mere artisan or specialist and a real seeker after truth." 2 
Then too, one day when I. I. Rabi "happened to be reading, for sheer pleasure, Maxwell's Treatise," he found a much-needed technique to measure the magnetic susceptibility of a crystal. On another occasion, struggling with quantum mechanics, he was rescued by a formula he found in his recreational reading of the mathematician C. G. Jacobi. And who can forget the question Rabi always asked students pondering a new scientific project: "Will it bring you nearer to God?"3

That was then, a cynical contemporary might remark, in the good old days. Yet contemporary physicists look back all the time to see from where the current situation has come and what presuppositions we now need to reexamine. Such questioning is, in fact, the living reality of history and philosophy. Furthermore, these issues are crucial to science education in general, especially for budding scientists. How can they make the transition from solving problems in textbooks to formulating and addressing bold new questions without ever having studied the ways such breakthroughs were actually-and not mythologically-made in the past?

Great physicists (such as those mentioned above) found specific insights and help in their predecessors, insights they often credited as formative (if not crucial) in their own work. One senses that they also drew a kind of courage from those who came before: If they could do it, perhaps I can too. Our aim in Physics in Perspective has been to reveal the living reality of physics, poised between past and future, embedded in its cultural context, and engaged in ongoing questioning. As Gerald Holton put it, "science is the product of actual human beings, rather than a decalogue handed down from on high." "It is one of the many ways that we human beings keep asking ourselves how and why did we get here? in order to understand what shall we do now?

It is not merely because physicists build on the work of their predecessors, therefore, that we should consider physics to be integrated with history. It is also because their aims are aligned. Historians and philosophers provide thick descriptions of the practice of physics. These accounts might not tell physicists the next step forward. But they do help physicists how steps can be taken.

\author{
Robert Crease \\ Joseph D. Martin \\ Peter Pesic
}

Publisher's Note Springer Nature remains neutral with regard to jurisdictional claims in published maps and institutional affiliations.

\title{
References
}

${ }^{1}$ Cited in a classic paper by Gerald Holton, "What Historians of Science and Science Educators Can Do for One Another," Science \& Education 12, no. 7 (2003), 603-16, on 607. 
Vol. 20 (2018) Editorial

${ }^{2}$ Cited in Don Howard, "Albert Einstein as a Philosopher of Science," Physics Today 58, no. 12 (2005): 34-40, on 34.

${ }^{3}$ Holton, "What Historians of Science" (ref. 1), 614-15.

${ }^{4}$ Holton, "What Historians of Science" (ref. 1), 607. 